\title{
ATIVIDADE DE DRAGAGEM E CIRCULAÇÃO DE MASSAS DE ÁGUAS OCEÂNICAS: POSSÍVEIS INFLUÊNCIAS NAS CARACTERÍSTICAS FÍSICO-QUIMIICAS NA PLATAFORMA CONTINENTAL INTERNA ADJACENTE À BAIÍA DE GUANABARA (RJ)
}

\author{
Dragging activity and circulation of ocean water masses: \\ possible influences on physicochemical characteristics on \\ inner shelf adjacent to Guanabara Bay (RJ)
}

\footnotetext{
Fabiane Bertoni dos Reis ${ }^{1,2^{*}}$, Leonardo Lima ${ }^{1,2}$, Estefan Monteiro da Fonseca ${ }^{1}$, André Belém $^{1}$

1 Programa de Pós-Graduação em Dinâmica de Oceanos e Terra Instituto de Geociências, Universidade Federal Fluminense. Avenida Gen. Milton Tavares de Souza s/nº - Gragoatá - Campus Praia Vermelha - Niterói - Rio de Janeiro. 2 -Bolsista do Projeto - Secretaria Nacional de Portos.

* Autor para correspondência: fabianebertoni@hotmail.com
}

\begin{abstract}
RESUMO
A atividade de dragagem é realizada em regiões portuárias para o aprofundamento, o alargamento e a manutenção do livre acesso das embarcações, bem como para a prevenção de acidentes e perdas, tendo, no entanto, como consequências mudanças na hidrodinâmica, nas características geofísicas e eventualmente alterações na geoquímica da água e do sedimento. Diante disso, o presente estudo visa caracterizar as massas d'água da entrada da Baía de Guanabara/RJ, Brasil, incluindo a área de descarte do material dragado da região. Esta análise inicial será referência para estudos posteriores de como essa atividade pode alterar e/ ou potencializar a circulação das águas e suas consequências. A partir de dados históricos e com o uso do software de análise oceanográfica Ocean Data View, foi possível observar a variabilidade sazonal natural da área, permitindo levantar questões que dão início a este tipo de análise, bem como a identificação de alguns impactos negativos e positivos no âmbito ambiental decorrente dessas correlações.
\end{abstract}

Palavras-chave: dragagem, ACAS, Baía de Guanabara. 


\section{ABSTRACT}

Dragging activity is carried out in port regions for the deepening, widening and maintenance of free access to vessels, as well as for accident prevention and losses. But it also results in changes in hydrodynamics, in geophysical characteristics and eventually, changes in water and sediment geochemistry. Therefore, the present study aims at to characterize the water masses at the entrance of Guanabara Bay/RJ, Brazil, including the region's disposal area for dredged material. This initial analysis will be a reference for further studies of how this activity may alter and/or enhance the circulation of water and the consequences. From historical data and using oceanographic analysis software Ocean Data View, it was possible to observe the natural seasonal variability of the area, raising questions that initiate this kind of analysis, as well as the identification of some negative and positive environmental impacts resulting from these correlations.

Keywords: dragging, SACW, Guanabara Bay.

\section{INTRODUÇÃO}

O modal de transporte marítimo necessita de uma estrutura composta por canais e vias marítimas, terminais e portos, fortemente dependente da profundidade (calado) e geometria hidroviária. Esse sistema permite a circulação de mercadorias, bens e pessoas, sendo de extrema importância para o desenvolvimento da economia local, nacional e global (Porto \& Teixeira, 2002). Contudo, para que as navegações ocorram de forma eficaz e segura, é fundamental que as vias de circulação estejam livres tanto em relação a sua profundidade quanto a sua largura.

Sabe-se que o processo de deposição de sedimentos no fundo de estuários e baías é natural (Godoy et al., 2012). Porém, esse processo pode ser acelerado por ações antrópicas, e a taxa deposicional está associada às dinâmicas internas do oceano, como correntes e variação das marés, por exemplo, e às dinâmicas externas a ele, como variabilidade climática, precipitação e sazonalidade. O uso e a ocupação da faixa costeira podem ainda modificar o balanço hídrico, o escoamento natural das águas pluviais e fluviais, aumentando ou diminuindo o aporte de sedimentos para os estuários e o oceano, além de incrementar com matéria orgânica advinda dos efluentes domésticos. Nesse complexo processo de influências exógenas e endógenas, as hidrovias tendem a assorear mais rapidamente, necessitando de manutenção por meio de dragagens.

Tanto a manutenção de uma geometria hidroviária quanto a sua alteração (no caso de aprofundamento, por exemplo) interferem diretamente na temperatura e na salinidade, variáveis que caracterizam o ambiente no contexto físico-químico e acabam influenciando nos processos biogeoquímicos associados, como, por exemplo, produtividade da biota, composição bacteriana e todas as reações subsequentes à presença ou ausência desses organismos (Goes Filho, 2004).

As atividades de dragagem têm como finalidade a limpeza, a desobstrução, a remoção, o derrocamento ou a escavação de material do fundo de rios, lagos, mares, baías e canais, removendo rochas e sedimentos e depositando em local de despejo apropriado (Marinha do Brasil, 1998). Existem diferentes tipos de dragas que são usadas dependendo da sua finalidade, do tipo da área selecionada, bem como da composição sedimentar do 
material a ser dragado (i.e., granulometria e a proporção entre silte, argila, areia, cascalho e rochas). Estas podem trabalhar de forma mecânica, hidráulica ou mista. Independentemente do tipo utilizado, durante todo o processo, o ambiente em questão sempre está sujeito a algum impacto direto ou indireto, tanto durante quanto após a atividade de dragagem. A partir da análise de Torres (2000) em relação aos artigos de Davis, Macknight e IMO (1990) e Bray, Bates e Land (1997), alguns desses impactos podem ser classificados nas seguintes categorias:

- Dispersão e deposição de sedimentos ressuspendidos;

- Alteração na batimetria do local;

- Efeitos sinérgicos sobre a linha de costa;

- Perda de habitats de fundo e impactos sobre recursos pesqueiros.

Apesar de citados alguns impactos de caráter negativo, é possível que em algumas situações as atividades de dragagem possam propiciar um impacto positivo, à medida que permitem a recirculação das águas e diminuição do tempo de residência, a renovação de nutrientes importantes para a cadeia trófica, a melhoria na taxa de oxigenação das águas, assim como impactos de caráter recreativo, turístico e comercial.

Com esse objetivo e para auxiliar no entendimento dos impactos das atividades de dragagem sobre o meio, é necessário compreender primeiro as características naturais do ambiente, principalmente reconhecer as massas d'água presentes e sua variabilidade natural, compreender as características que elas trazem consigo e o quanto elas podem influenciar na composição biogeoquímica da área de influência direta da dragagem.

Este trabalho explora essas características físicas históricas e busca correlações preliminares com as atividades de dragagem ocorridas na área portuária do Rio de Janeiro em 2016 e 2017, para auxiliar no entendimento do comportamento e da dispersão do material dragado disposto na área F, localizado na Plataforma Continental Interna ao largo da Baía de Guanabara, no Rio de Janeiro (RJ).

\section{MATERIAIS E MÉTODOS}

Os dados utilizados neste trabalho foram obtidos através do portal do World Ocean Database organizados e disponibilizados pela National Oceanographic Data Center (NODC/NOAA) ${ }^{1}$. Os tipos de dados escolhidos e utilizados neste trabalho são oriundos de campanhas oceanográficas realizadas na área de estudo, divididos especificamente em coletas com sondas do tipo CTD (Conductivity, Temperature Depth), além de garrafas de Niskin e Nansen (tipo OSD - Ocean Station Data) e perfiladores mecânicos (tipo MBT Mechanical Bathythermographs, que também incluem termógrafos digitais). Na plataforma do NODC, foram também selecionados dados dentro da área de estudo que compreende a plataforma interna adjacente à entrada da Baía de Guanabara.

Para essa caracterização foi utilizado o software de análise oceanográfica Ocean Data View (ODV) desenvolvido por Reiner Schlitzer. Foram elaborados diagramas TS para identificação das massas d'água e perfis transversais à plataforma para caracterização da estrutura vertical de salinidade, temperatura e densidade.

Disponível em: https://www.nodc.noaa.gov/ >Access Data>World Ocean Database >sorted geographically> WMO 5204. 
Os dados foram selecionados de acordo com a sua qualidade (foram excluídos outliers e dados sem o controle de qualidade do NODC) no período de 1950 até os anos mais recentes e divididos por estação do ano. Considerou-se o período de inverno composto pelos meses de junho, julho, agosto e de verão composto pelos meses de dezembro, janeiro e fevereiro.

A partir do Diagrama TS é possível identificar as massas de águas presentes na região de estudo, e o padrão de análise segue a metodologia recomendada pela Comissão Oceanográfica Intergovernamental (COI), com o aval do Comitê Científico de Pesquisas Oceânicas (SCOR) e da Associação Internacional de Ciências Físicas dos Oceanos (IAPSO), adotando a Equação Termodinâmica Internacional da Água do Mar - 2010 (TEOS-10 ) como descrição oficial das propriedades da água do mar. As variáveis utilizadas foram temperatura conservativa $(\theta)$ e salinidade absoluta $\left(S_{A}\right)$ (http://www.teos-10.org/). $O$ diagrama também apresenta isopicnais para facilitar a identificação das massas d'água.

Para delimitar a área de estudo, traçou-se uma seção transversal à costa (Figuras 1 e 3) que corresponde a uma linha de aproximadamente $40 \mathrm{~km}$ a partir da entrada da Baía de Guanabara, com aproximadamente $20 \mathrm{~km}$ de largura. Todos os dados nessa área foram considerados como parte da mesma seção transversal. Foram utilizadas as mesmas variáveis citadas anteriormente, a fim de manter um padrão nos resultados. Os dados foram interpolados em uma grade regular com o Diva (Data-Interpolating Variational Analysis) do ODV.

\section{RESULTADOS E DISCUSSÕES}

\section{Verão}

A partir da inserção dos dados e dos critérios selecionados, foi possível obter os seguintes gráficos e observar, a partir da Figura 1, que no período de verão é evidente e bem definida a entrada da Água Central do Atlântico Sul (ACAS) de acordo com suas características, que tendem a ter temperaturas de $6^{\circ} \mathrm{C}$ a $19^{\circ} \mathrm{C}$ e salinidade de 34 a 36 . A massa acima dessa (coloração do amarelo ao vermelho) aparenta ser a Água Tropical (AT) por apresentar uma faixa aqui representada em tons de verde seguindo para o amarelo com temperaturas entre $19{ }^{\circ} \mathrm{C}$ e $26^{\circ} \mathrm{C}$ e salinidade $>36$ (Silva; Albuquerque; Cavalheiro \& Hansen, 1984).

O Diagrama TS (Figura 2) também indica a entrada de ACAS, apresentando faixas semelhantes de temperatura e salinidade e densidade nessa área entre 26 e $27 \mathrm{~g} / \mathrm{cm}^{3}$, ou seja, uma água mais fria e mais salina em maiores profundidades, quando comparada com a maioria dos pontos restantes do gráfico.

\section{Inverno}

De acordo com a Figura 3, que representa o período do inverno, também se percebe a presença da ACAS, que adentra na Plataforma Continental Interna, porém de uma maneira mais heterogênea quando comparada com o período de verão, e um pouco mais compartimentada na coluna d'água (sentido vertical). Nessa mesma figura é possível observar temperaturas mais elevadas $\left(22^{\circ} \mathrm{C}\right)$ na área da boca da baía e chegando a 60 metros de profundidade, enquanto no verão essa mesma temperatura só foi observada em águas mais superficiais. 
Figura 1 - Seção transversal durante o verão. Linhas de contorno indicam a salinidade absoluta e as cores indicam a temperatura conservativa

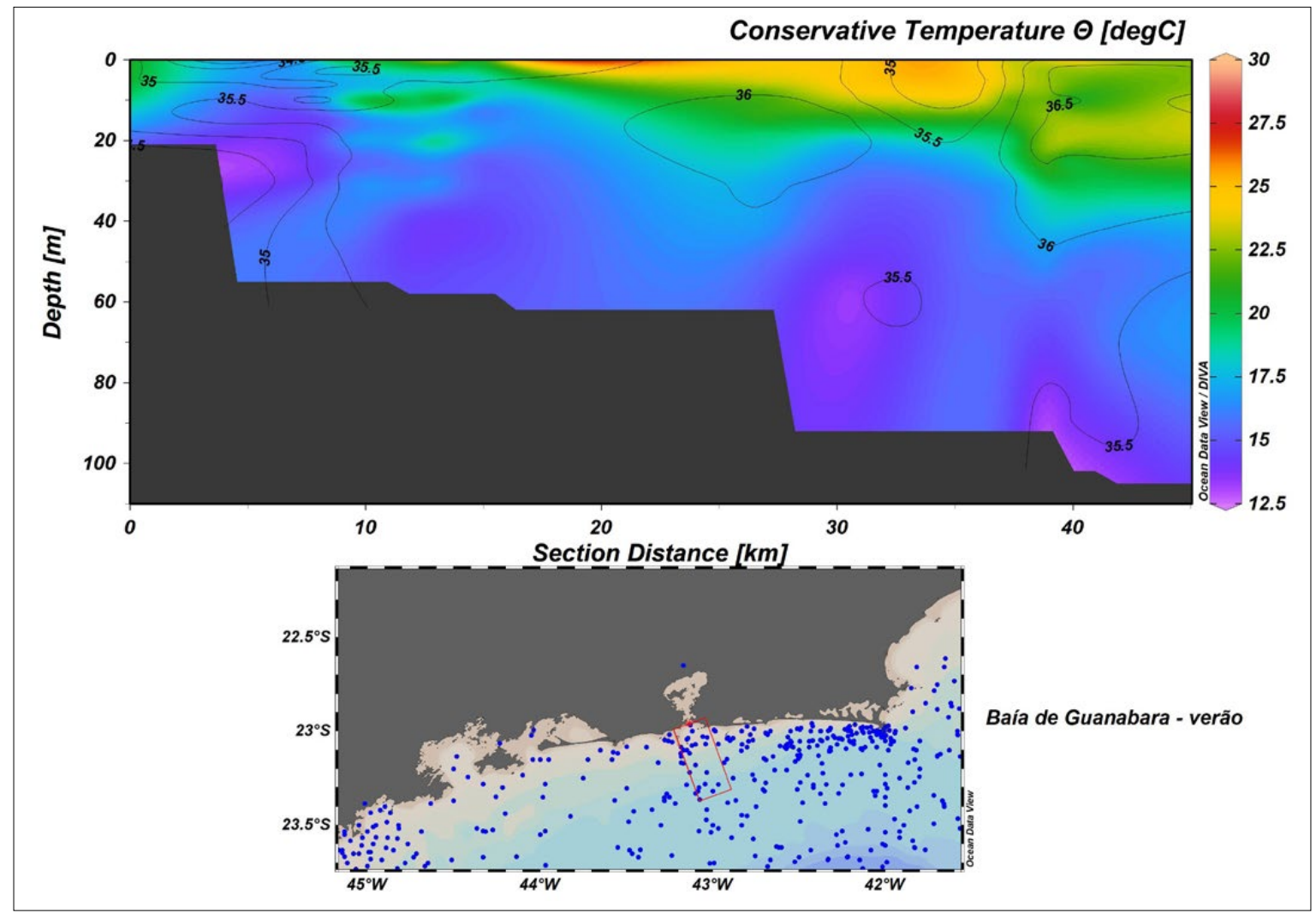

Figura 2 - Diagrama TS da seção - verão.

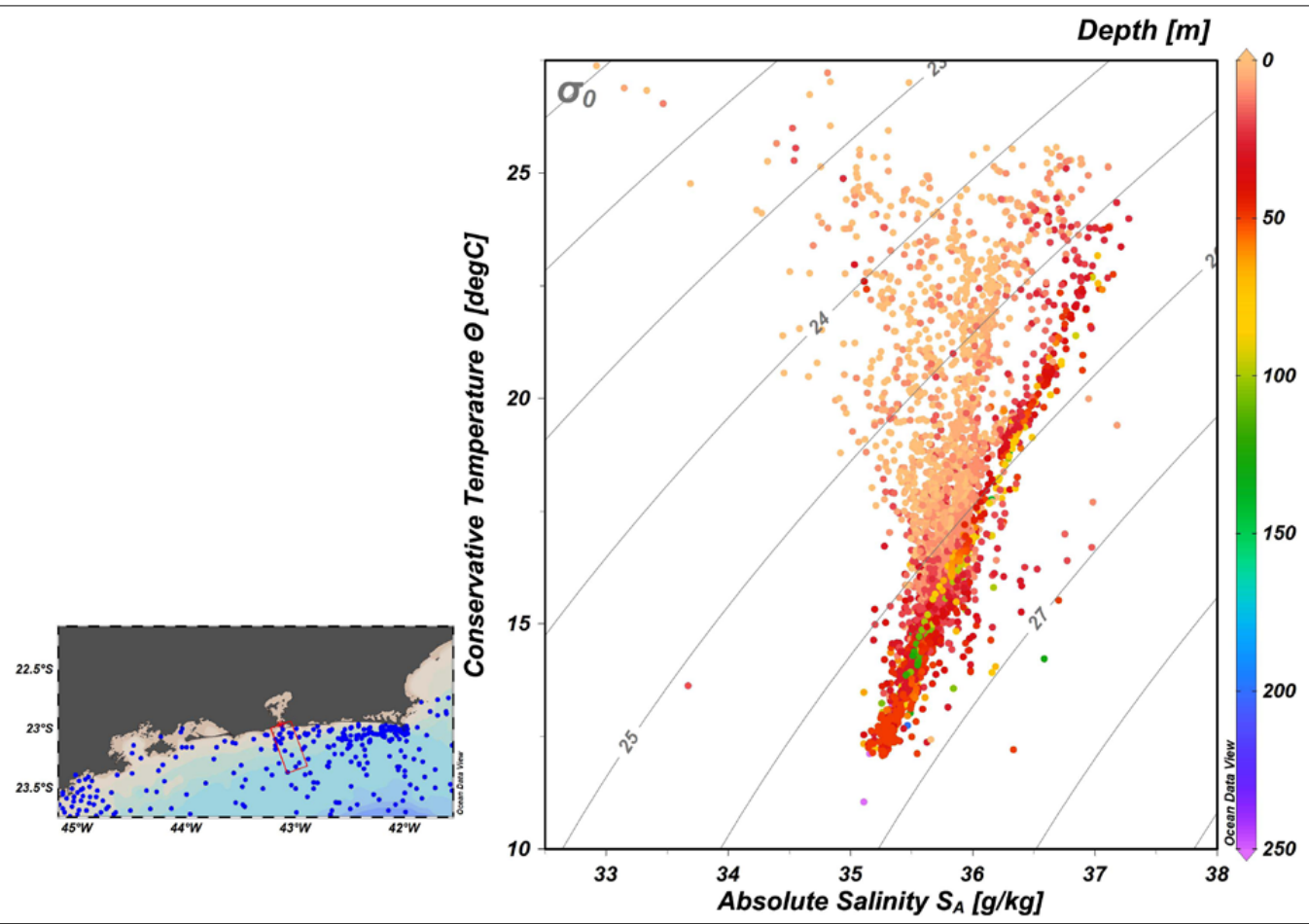


Figura 3 - Seção transversal durante o inverno. Linhas de contorno indicam a salinidade absoluta e as cores indicam a temperatura conservativa.

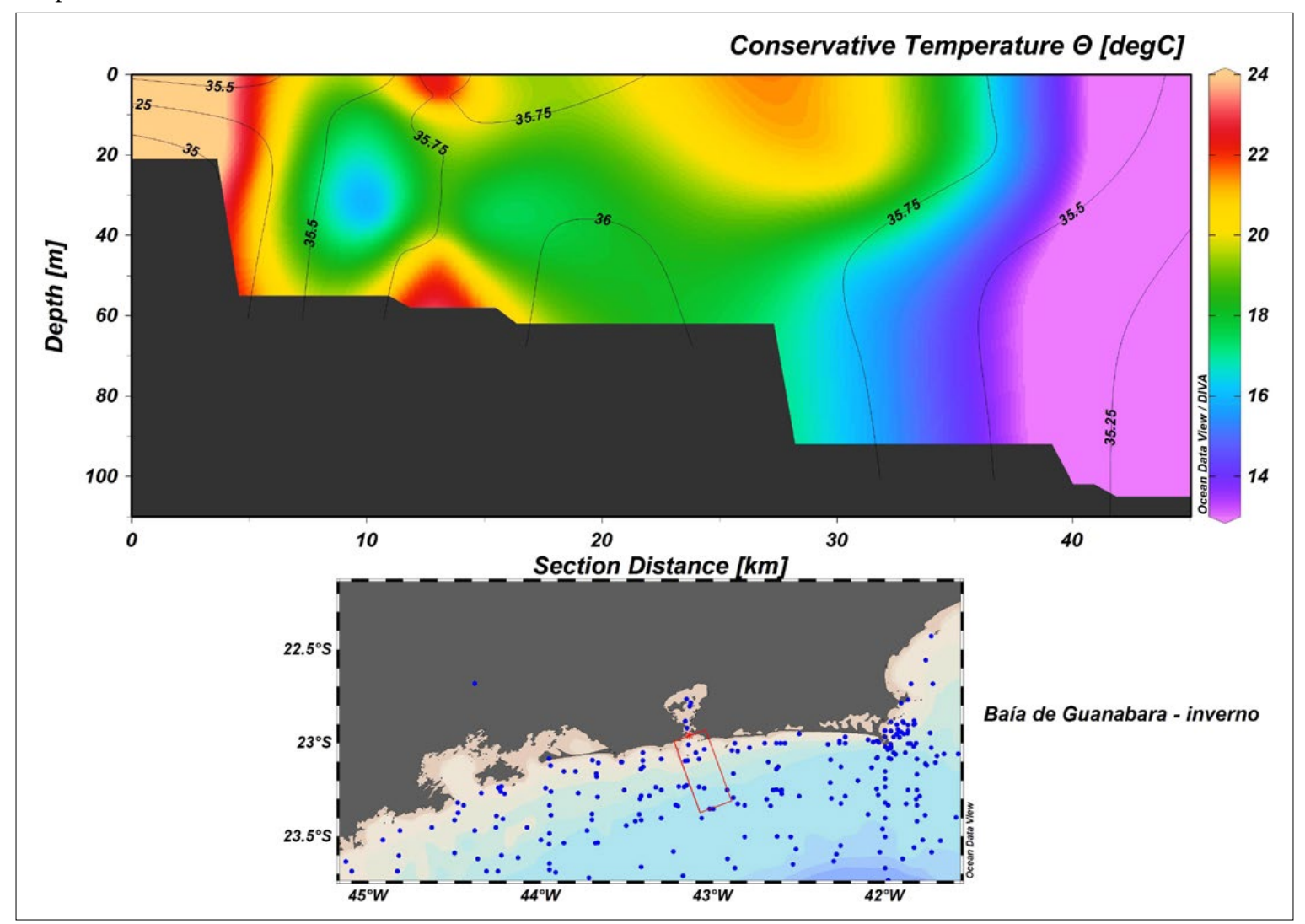

Em relação ao Diagrama TS (Figura 4), também se torna evidente a presença de ACAS posicionada na faixa de densidade de 26 e $27 \mathrm{~g} / \mathrm{cm}^{3}$, e o Diagrama apresenta-se mais definido, como pontos menos difusos.

De acordo com os gráficos apresentados é possível observar a presença da ACAS tanto no verão quanto no inverno. Porém, no gráfico, durante o verão esta é mais bem definida e estratificada horizontalmente, seguindo a lógica da densidade. A configuração apresentada no verão mostra claramente a influência da ressurgência no local. Essa ressurgência é uma característica oceanográfica da região de Cabo Frio, onde as águas frias e ricas em nutrientes (ACAS) afloram (Coe; Carvalho; Souza \& Soares, 2010) e percorrem a costa no sentido sudoeste, trazidas pela Corrente do Brasil, passando pela área da Baía de Guanabara (Lorenzzetti \& Gaeta, 1996) e alcançando a área próxima à Ilha de São Sebastião, em São Paulo (Elias, 2009).

Observa-se uma inconformidade no gráfico de inverno (Figura 3) que precisa ser bem mais estudada. Percebe-se, de modo geral, que a distribuição da salinidade apresenta-se de forma incoerente se considerarmos que nessa região, no inverno, a tendência seria encontrar águas mais salinas, devido ao fato de ter pouca chuva, e sendo mais salinas, são mais densas, e se são mais densas, deveriam se posicionar mais ao fundo (Silva; Albuquerque; Cavalheiro \& Hansen, 1984). Para esta análise, é importante observar dados de vento e considerar o Bombeamento de Ekman, mecanismo a ele associado, capaz de provocar divergência na coluna d'água (Castelão \& Barth, 2006). 


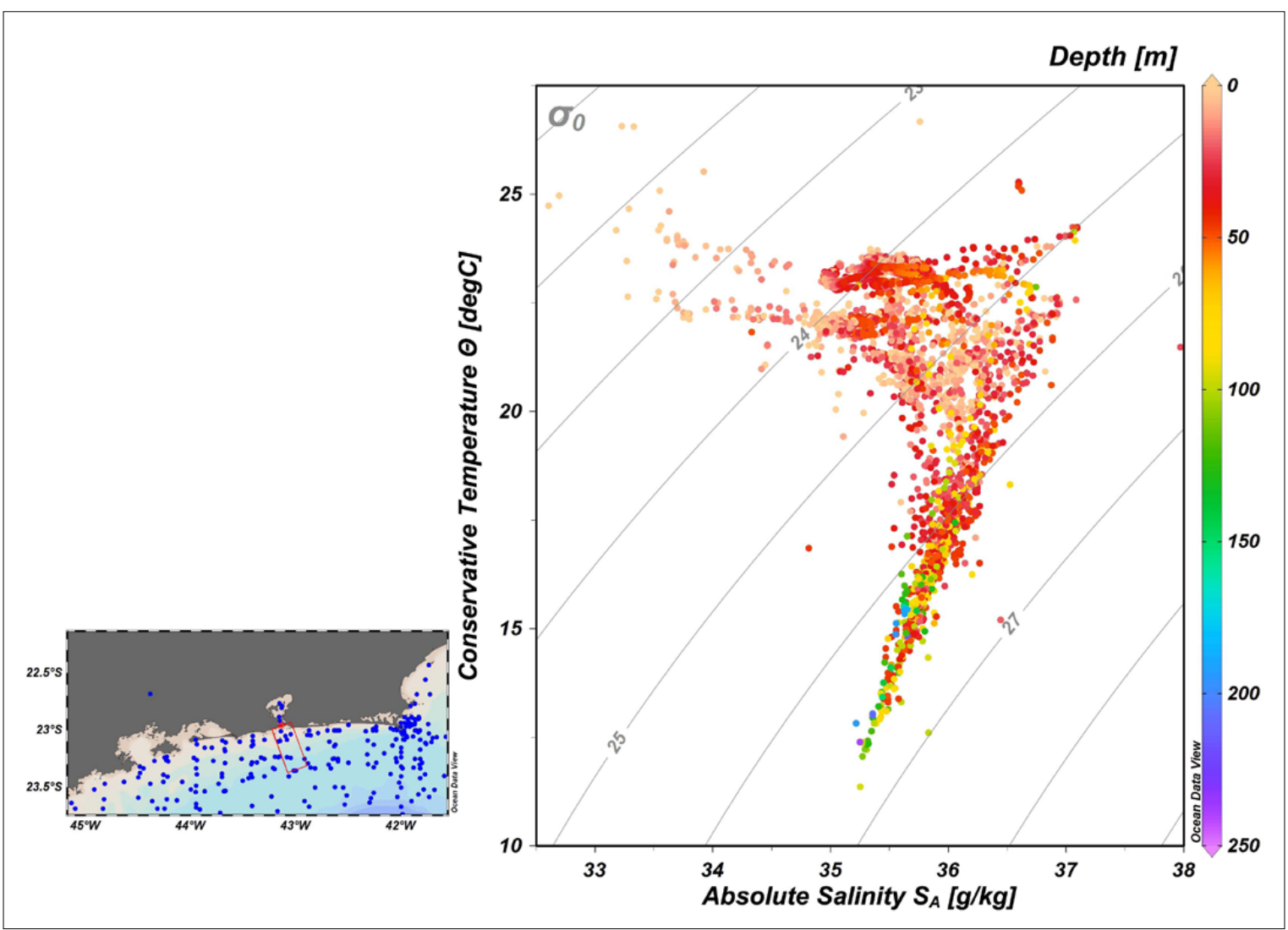

A forma do Diagrama TS ressalta quantas massas de água estão envolvidas no local do estudo, porém seria interessante para uma análise mais aprofundada fazer um cálculo (Miranda, 1985) para extrair a porcentagem de contribuição de cada massa de água identificada.

Acredita-se que novas interpolações devam ser realizadas estipulando padrões mais bem definidos para que a área seja fielmente comparada nas diferentes estações, bem como observar novamente os dados, a fim de identificar a sua sensibilidade.

Por ser a baía um ambiente mais confinado, seria interessante correlacionar com dados de enchente e vazante de marés (Weisberg \& Zheng, 2006) para verificar o quanto esse movimento auxilia na entrada de ACAS.

\section{CONSIDERAÇÕES FINAIS}

Um dos efeitos da dragagem de aprofundamento e ampliação de canais navegáveis é o aumento da circulação do fluxo de sal associado, devido à alteração da batimetria. Para esta análise, futuros estudos serão realizados com dados mais atualizados e localizados na área dragada e dentro da Baía de Guanabara para verificar se a ACAS entra na baía, até onde ela consegue chegar e a sazonalidade dessa ocorrência, verificando-se principalmente a área onde foi dragada para ver a intensidade desse efeito, visto que, com sua chegada e a possível alteração na composição bacteriana desse ambiente, pode torná-la uma área mais salina, assim como com maior ou menor biodisponibilidade de elementos contaminantes 
que foram revolvidos do fundo ou que estão em suspensão no local ou na área de disposição final (bota-fora).

Será associado a este um futuro estudo com dados de $\mathrm{pH}$, oxigênio dissolvido, turbidez, nitrogênio e metais pesados. Também será verificado um monitoramento de ecotoxicidade realizado no período da última dragagem para verificar se houve alguma relação e alteração nos organismos.

Para auxiliar na compreensão da dispersão desses elementos dentro do ambiente confinado da baía, serão associados dados de maré, direção e alteração na velocidade das correntes, buscando verificar se os materiais particulados em suspensão são provenientes naturalmente do continente ou se está havendo um retorno do material dragado que foi disposto na área de bota-fora pela influência desses pulsos de entrada da ACAS. Avaliar a alteração na direção e na velocidade das correntes também é algo a ser considerado, bem como a tipologia do sedimento para estimar a sua proveniência.

Considerando a temática e os pontos abordados no início deste trabalho, juntamente com a análise dos gráficos gerados pelo software ODV, notou-se que as atividades de dragagem podem gerar impactos positivos e negativos. Sendo assim, para a efetivação desse tipo de atividade é necessária uma avaliação que contemple todas as consequências, a fim de ponderar a relevância, a necessidade e a frequência da realização de uma obra de dragagem nesse tipo de ambiente.

Portanto, cabe destacar a importância da eficiência na gestão, no gerenciamento dessas atividades, bem como no manejo do material dragado e sua disposição final. Acredita-se ser válida a realização de estudos prévios e integrados, a fim de identificar as tendências e as consequências nos âmbitos ambiental, econômico e social. Dessa forma, a aplicação de metodologias como a apresentada neste estudo é fundamental para o planejamento e o conhecimento integral da área, confrontando, assim, a real necessidade e resiliência desse ambiente e os impactos positivos e negativos associados a curto, médio e longo prazos.

\section{REFERÊNCIAS BIBLIOGRÁFICAS}

Brasil. Lei $n^{\circ}$ 11.610, de 12 de dezembro de 2007. Institui o Programa Nacional de Dragagem Portuária e Hidroviária. Disponível em: http://www.planalto.gov.br/ccivil_03/_ato20072010/2007/Lei/L11610.htm. Acesso em: maio 2011.

Bray, R.N.; Bates, A.D. \& Land, J.M. Dredging: a handbook for engineers. Inc. second edition, New York: John Wiley \& Son, 434 p., 1997.

Castelão, M.R. \& Barth A.J. Upwelling around Cabo Frio, Brazil: the importance of wind stress curl. Geophysical Research Letters, v. 33, p. 4, 2006.

Coe, H.H.G.; Carvalho, C.N. de; Souza, L.O.F. de \& Soares, A. Peculiaridades ecológicas da região de Cabo Frio. Revista Tamoios, São Gonçalo, v. 3, n. 2, 2010.

Davis, J.D.; MacKnight, S. \& IMO staff. Environmental considerations for port and harbor developments. World Bank Technical Paper, n. 126, 83 p., 1990.

Godoy, J.M. et al. Guanabara Bay sedimentation rates based on $210 \mathrm{~Pb}$ dating: reviewing the existing data and adding new data. Journal of the Brazilian Chemical Society, v. 23, n. 7, p. 1265-1273, 2012. 
Goes Filho, H.A. Dragagem e gestão dos sedimentos. Dissertação de mestrado, Instituto Alberto Luiz de Pós-Graduação e Pesquisa de Engenharia, Universidade Federal do Rio de Janeiro, Rio de Janeiro, RJ, 2004.

Lorenzzetti, J.A. \& Gaeta, S.A. The Cape Frio upwelling effect over the South Brazil Bight northern sector shelf waters: a study using AVHRR images. International Archives of Photogrammetry and Remote Sensing, Vienna, p. 448-453, 1996.

Marinha do Brasil. Normam-11/DPC. Portaria $n^{\circ}$ 27, de 12 de maio de 1998. Disponível em: https://www.dpc.mar.mil.br/normam/N_01/normam01.pdF. Acesso em: jan. 2012.

Miranda, L.B. Forma da correlação t-s de massas de água das regiões costeira e oceânica entre o Cabo de São Tomé (RJ) e a Ilha de São Sebastião (SP). Bol. Inst. Oceanogr., São Paulo, v. 33, n. 2, p. 105-119, 1985.

Porto, M.M. \& Teixeira, S.G. Portos e o desenvolvimento. São Paulo: Lex Editora, 2002.

Silva, L.C.F.; Albuquerque, C.A.M.; Cavalheiro, W.W. \& Hansen, C.M.P. Gabarito tentativo para as massas de água da costa sudeste brasileira. Anais Hidrográficos, Tomo XLI, DHN, 1984.

Silvia, M.C. et al. Dragagem e conflitos ambientais em portos clássicos e modernos: uma revisão. Sociedade E Natureza, Uberlândia, a. 24, n. 3, p. 519-534, set./dez. 2012.

Torres, R.J. Uma análise preliminar dos processos de dragagem do Porto de Rio Grande, RS. Dissertação de mestrado, Fundação Universidade Federal do Rio Grande, 190 p., Rio Grande do Sul, 2000.

Weisberg, R.H. \& Zheng, L.Y. Circulation of Tampa Bay driven by buoyancy, tides, and winds, as simulated using a Finite Volume Coastal Ocean Model. Journal of Geophysical Research, v. 111, C01005. 2006. 